\title{
Design of Weather Monitoring Sensors and Soil Humidity in Agriculture Using Internet of Things (IoT)
}

\author{
Yoga Alif Kurnia Utama ${ }^{1}$, Yonatan Widianto ${ }^{2}$, Yulius Hari ${ }^{3}$, Muhammad Habiburrahman ${ }^{4}$ \\ Engineering Faculty, Widya Kartika University ${ }^{1,2,3,4}$ \\ yoga.alif@widyakartika.ac.id ${ }^{1}$, yonatan@widyakartika.ac.id², yulius.hari.s@widyakartika.ac.id², \\ habibsantri@gmail.com ${ }^{4}$
}

\begin{abstract}
One of the developments in internet technology at the moment is the Internet of things (IoT). IoT is a concept that aims to expand the benefits of internet connectivity that is connected continuously and can monitor a system or object. As for capabilities such as data sharing, remote control, including monitoring a system. Because Indonesia is an agricultural country, this study tries to make a monitoring of a smart farmer system that helps people monitor plants on their farms. This system will monitor weather parameters such as temperature and humidity conditions, as well as soil moisture conditions. If soil moisture is reduced due to heat, then water will automatically be pumped and flow to the plant. Farm owners can also monitor the condition of their plants in real time remotely through the Blynk application media, Facebook website, and Twitter. Based on the test results, the system can measure the environmental conditions of plants, can connect to the internet and be able to send data from sensor measurements to the Blynk application, Facebook website and Twitter. With the development of these systems and devices, it is hoped that the farmers or the community can monitor the environmental conditions of the plants
\end{abstract}

Keywords: Internet of things (IOT), Smart Farmer, Weather Sensors and Soil Moisture, Microcontroller.

\section{Preliminary}

The rapid development of science and technology has had a great impact on human life. In the development of technology, electronics and computers, effectiveness and efficiency are the references in the use and use of technology so that it can achieve optimal results. To be able to realize this, a device and a system are needed that can process data accurately. Along with the increasing needs of the community in the fields of agriculture and plantations, a system that is expected to facilitate and improve effectiveness in farming or gardening is needed. One of them is currently developing rapidly is the internet of things (IoT). The main challenge in loT is to facilitate the exchange of data between the physical world (hardware) and the world of information such as sending data obtained from electronic equipment through an interface between the user and the equipment.

The sensor collects physical raw data from real-time checking and converting it into understandable format machines so as to facilitate the exchange of data between various forms of data formats (Thing) [3]. IoT appears as a big issue on the Internet, it is expected that billions of things (hardware) or objects will be equipped with various types of sensors that can connect to the internet through networks and 
technology support, such as embedded sensors and actualization, in some cases real-time data flow will automatically be generated by connected things and sensors. Of all the activities in loT, that is to collect the correct raw data in an efficient way, but more important is to analyze and process raw data into more valuable information [4]. In the field of agriculture and plantations where the concept of the internet of things is expected to reduce human work in several ways such as irrigation, temperature detection, controlling humidity which was originally done simply and manually, can be replaced by more thorough systems and devices.

Indonesia is one of the countries in the equator. Because it is crossed by the equator, the climate in Indonesia includes a tropical climate. This tropical climate makes agriculture one of the most superior commodities in Indonesia. Therefore it is not surprising that the majority of the population works in agriculture, fisheries, and plantations. The community involved in this field, especially agriculture and plantations, in the processing and maintenance of almost all plants manually starting from irrigation, pest eradication, providing fertilizers and medicines, while to know the quality of the soil and nutrients needed by the plant itself cannot be known to farmers. Therefore, the research tries to help the community, especially farmers, by making a device consisting of weather sensors and soil moisture in order to help farmers monitor their agricultural results in real time because the sensor data is sent and displayed on the blynk application on mobile phones. Android, and can be checked through the website, Facebook and Twitter.

\section{Literature Review}

Internet of things (IOT) is a concept that aims to expand the benefits of continuously connected internet connectivity. As for capabilities such as data sharing, remote control, etc., including objects in the real world. For example, food, electronics, any collection of equipment including living things that are all connected to local and global networks through embedded and always active sensors, the term internet of things was originally conceived by Kevin Ashton in 1999.

The main challenge in loT is to facilitate the exchange of data between the physical world (hardware) and the information world. Like how to process data obtained from electronic equipment through an interface between the user and the equipment. The sensor collects physical raw data from real-time scenarios and converts it into understandable formatting machines so that it will be easily exchanged between various forms of data formats (Thing) [3].

IoT appears as a big issue in the world of communication and information, it is expected that billions of physical things or objects will be equipped with various types of sensors that can be connected to the internet through networks and technology support, such as embedded sensors and actualization, in some cases real data flow -time will be automatically generated by connected things and sensors. Of all the activities in loT, that is to collect the correct raw data in an efficient way, but more important is to analyze and process raw data into more valuable information [4].

Smart Farmer is a prototype that will be made with electronic components consisting of several sensors needed in the agricultural field and the NodeMcu microcontroller. This device can connect with users through internet connectivity and transmit data from these environmental conditions, the concept is included in the concept of the internet of things.

Data obtained from the sensor will be sent periodically and read on the Blynk application and posted on Facebook and Twitter sites. Apart from reading data from sensors, there will be a condition where a 
Yoga Alif Kurnia Utama, Yonatan Widianto, Yulius Hari, Muhammad Habiburrahman; Design of Weather Monitoring Sensors and Soil Humidity in Agriculture Using Internet of Things (IOT), Transactions on Machine Learning and Artificial Intelligence, Volume 7 No 1 February, (2019); pp: 10-20

moisture sensor checks soil moisture, if soil moisture is lacking, or the soil conditions are too dry from the specified standard it will be checked by the system and will pump water to sufficient water content or soil moisture in the plant.

In making this smart farmer, the required components include microcontroller NodeMcu, Digital Humidity And Temperature 11 (DHT11) sensor, and soil moisture sensor (soil moisture sensor), the advantage of using NodeMcu is the wifi module integrated in its components, making it very easy sending data to the server via the internet network, besides that there is a Blynk application that will be used by the author to monitor plant environment data, this application is an Android smartphone application that can be configured as needed.

Smart farmer is included in the information technology section where generally there are input, process and output flows, as in the diagram below. In this case, what acts as an input is the sensor, the DHT11 sensor, and the soil moisture sensor, then the processing part is the microcontroller NodeMcu, then the output is the data display on the Blynk application and posting the status on the Twitter website and Facebook.

\section{Method}

The device made in this study refers to the block diagram in Figure 1 below. This tool consists of a weather sensor in the form of a DHT 11 sensor that will measure temperature and humidity. In addition, there is a soil moisture sensor that will measure the level of soil moisture on agricultural land. These sensor data will determine how long the water pump will turn on to irrigate plants and nutrients. The water pump is turned on by using a relay so the water pump can be turned off and turned on automatically. In reading the sensor and controlling the actuator in the form of a water pump, a Nodemcu microcontroller is needed. This microcontroller was chosen because it can be directly connected to the internet network. The internet network is used to send sensor data and actuator status to an android application called Blynk and several websites namely Facebook and Twitter.

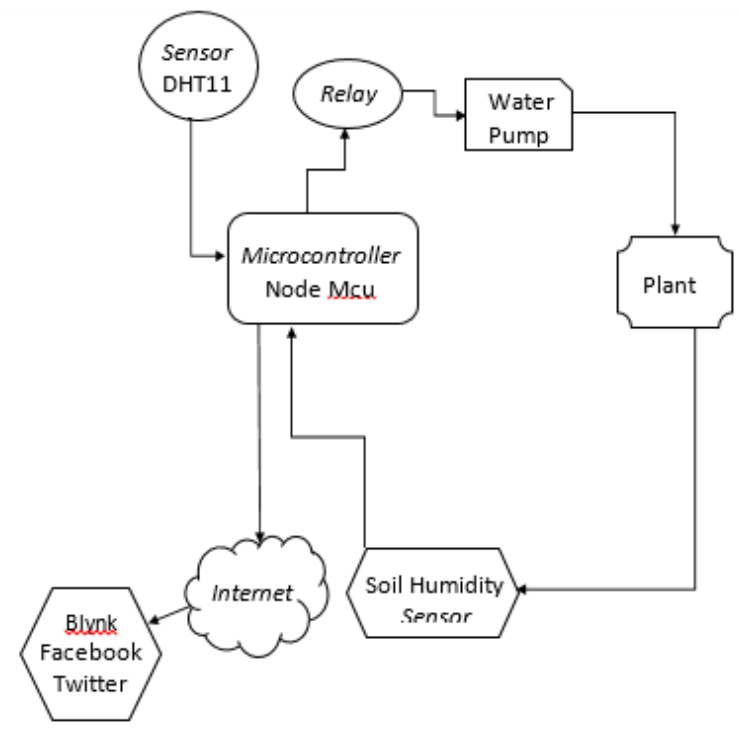

Figure 1. Block Tool Diagram 
In designing a tool with the appropriate function shown in the block diagram in Figure 1, several sequences are needed. The series is described as follows:

\section{DHT 11 Sensor Series}

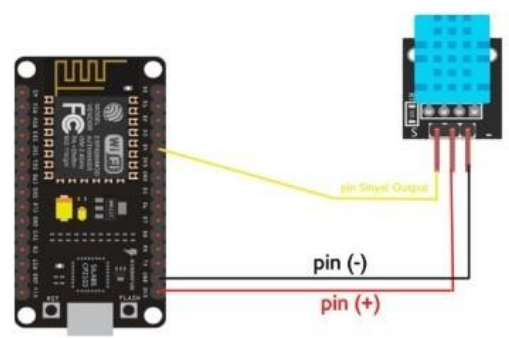

Figure 2. DHT11 and NodeMcu Sensor Circuits

DHT 11 sensor has 3 pins, pin (+) connected to 3v3 NodeMcu power output, then pin (-) connected to GND (Ground) NodeMcu, finally, S pin on DHT11 is connected to pin D4 on NodeMcu which functions as a receiver of value data from sensor DHT11.

\section{Sensor Soil Moisture Series}

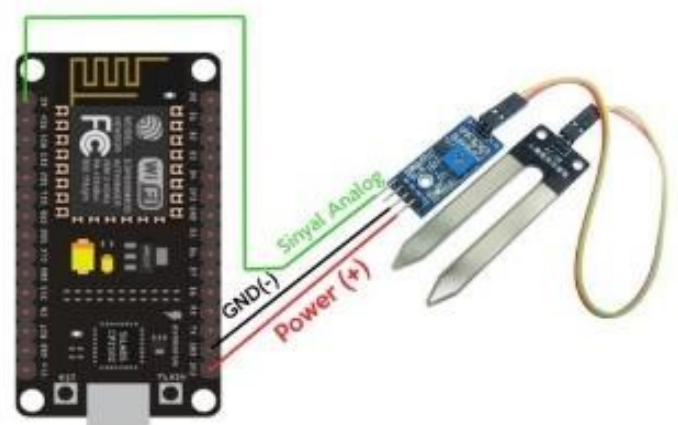

Figure 3. NodeMcu circuit with Sensor Soil Moisture

Soil moisture sensor is used to measure the humidity on the ground, the circuit as shown above.

\section{Pump Circuits}

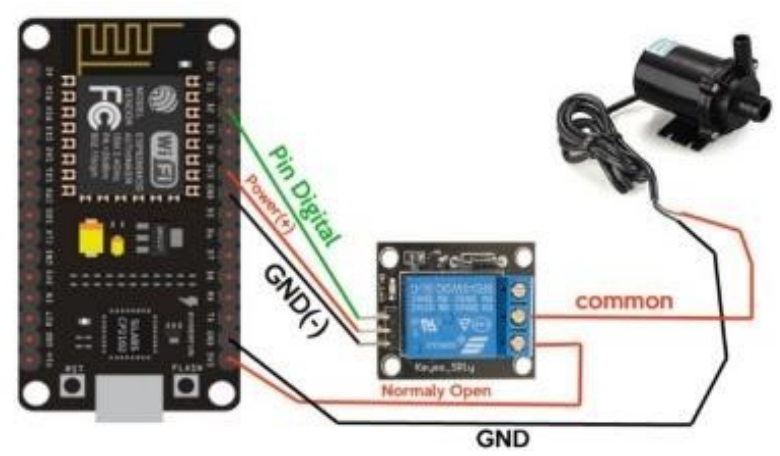

Figure 4. NodeMcu circuit with relay and pump

The circuit aims to activate and deactivate the pump, Relay is used to adjust the condition of ON and OFF of the pump. Writing program code using the LUA language, NodeMcu also supports writing in C, the same 
Yoga Alif Kurnia Utama, Yonatan Widianto, Yulius Hari, Muhammad Habiburrahman; Design of Weather Monitoring Sensors and Soil Humidity in Agriculture Using Internet of Things (IOT), Transactions on Machine Learning and Artificial Intelligence, Volume 7 No 1 February, (2019); pp: 10-20

as used on Arduino. To run the series, some programming syntax must be made. Some of the syntax in the program that has been made is described as follows:

\title{
1. Device Declaration
}

In this first step, we define the Blynk application via \#define BLYNK_PRINT Serial by writing \#include $<$ BlynkSimpleEsp8266.h>, then the Wifi module to communicate data over the internet. The writing of the line of code is as follows.

\author{
//Blynk dan ESP \\ \#define BLYNK_PRINT Serial \\ \#include <ESP8266WiFi.h> \\ \#include <BlynkSimpleEsp8266.h>
}

\section{DHT Sensor Declaration 11}

Defines the variables needed to read the DHT11 sensor, calls module \#include "DHT.h", then defines pin \#define DHTPIN 2, pin 2 or GPIO 2 equals D4, for the NodeMcu pin schema, \#define DHTTYPE DHT11 defines the sensor the DHT11 sensor is used. Following is a fragment of the DHT11 code.

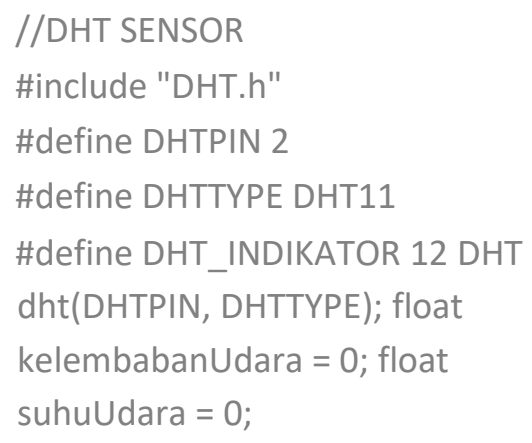

\section{Declaration of Humidity Sensor}

The code line below defines which pins are used to read soil moisture sensors or soil moisture sensors.

//SOIL SENSOR \#define soil_pin

A0 int kelembabanTanah = 0 ;

\section{Declaration of Pump Relays}

The pump functions to irrigate if the soil lacks water, in the code line pin 4 or GPIO 4 means pin D2 to connect the NodeMcu to the relay input pin, then the relay is connected to the pump.

\section{//RELAY}

//\#define POMPA_PIN 12

\#define POMPA_PIN 4 \#define

TIME_PUMP_ON 7 boolean status

Pompa = 0; 


\section{Timer Declaration}

The timer is used to read data periodically in settings using milliseconds, so the line of code above defines the timer.

\section{//TIMER}

\#include <SimpleTimer.h>

\#define BACA_DATA_DHT_SOIL 2

\#define KIRIM_DATA_SENSOR 1

\#define AUTO_CONTROLL 6

SimpleTimer timer;

\section{Variable Declarations and Auto Control Values}

In the variable below, it is defined that the drought limit is if the dry level is less than 30 , and the wet limit is at level 80.

\section{//VALUE AUTO CONTROL SOIL SENSOR}

\#define KERING 30

\#define BASAH 80

\section{Declaration of Wifi Connection}

In the code line below, defined access point information that will be addressed as an internet server along with a token or auth code provided by Blynk when registering, to be able to be accessed by the Blynk application.

\section{//KONEKSI}

char auth[] = "dc18d91e662549149e7c5bf4b5c9781c"; char

ssid[] = "LAB ELEKTRO";

char pass[] = "elektro123";

\section{Function Setup}

In the code line below it functions as the basic setup of the program as needed, there is Serial.begin (9600) to activate the display of the NodeMcu terminal on port 9600. Serial.println ("Smart Farmer"), Serial.println ("... Ready Application" ) will appear first when activating the terminal, then call the Blynk function from the Blynk module to connect to the internet, in the Blynk.begin code line (auth, ssid, pass) auth, ssid, and pass, dht.begin to activate the dht sensor reading, then define pinMode for soil moisture sensors and DHT sensors as OUTPUT, and finally start process to call the start process function which functions to call a collection of functions that have been joined to the start process function.

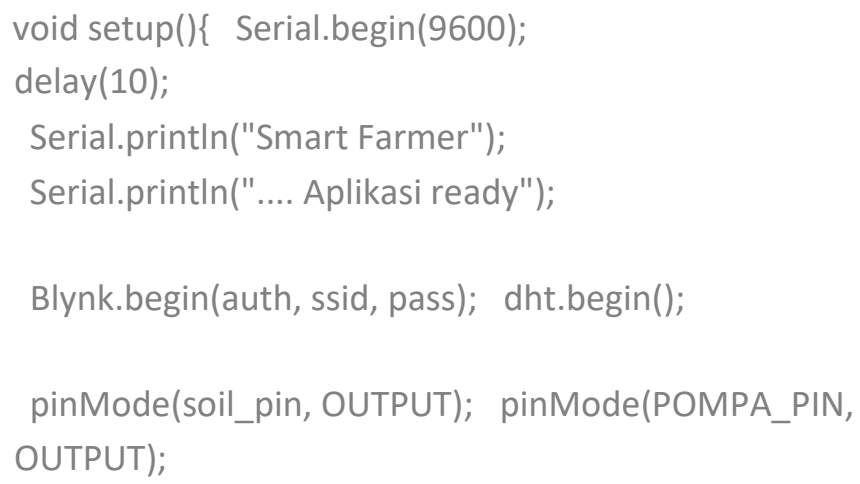


Yoga Alif Kurnia Utama, Yonatan Widianto, Yulius Hari, Muhammad Habiburrahman; Design of Weather Monitoring Sensors and Soil Humidity in Agriculture Using Internet of Things (IOT), Transactions on Machine Learning and Artificial Intelligence, Volume 7 No 1 February, (2019); pp: 10-20

startProses();

\}

\section{Function Start Proses}

The start process function functions to collect all the functions created manually according to the needs and then join with the timer to update data periodically.

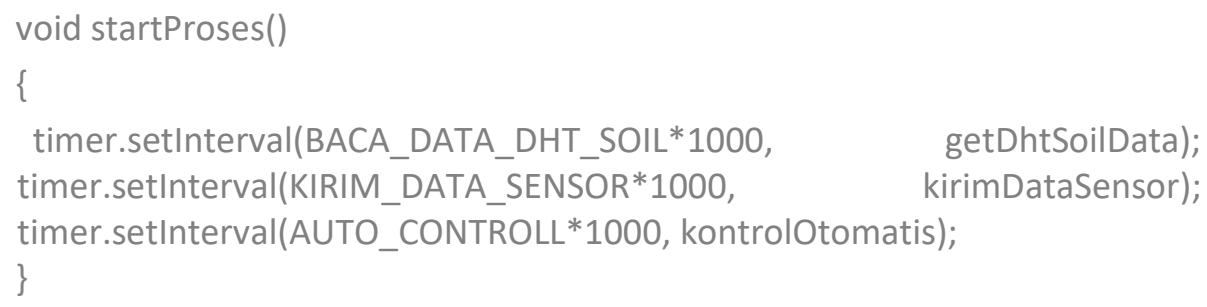

10. The function of the Pump Button from the Application

The above function is useful for activating the pump through the Blynk application. In the application a virtual button is made, where the button is useful to turn on the pump manually, the virtual button is declared with a virtual pin 6 , therefore, so that the button on the application can be read in the program, the parameter number 6 is created in the BLYNK_WRITE line (6).

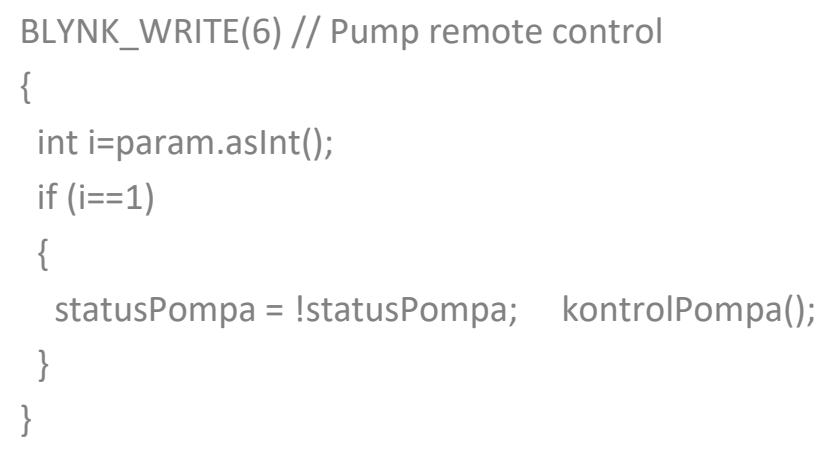

\section{Function of reading DHT11 sensors}

The function above is used to read the values of DHT11 sensors and soil moisture, to read the air temperature using dht.readTemperature () which is declared with the temperature variable Air, and dht .readHumidity () which is declared with variable humidity. then the statement failed to read the DHT sensor. To send notifications to social media, there is the Blynk.tweet class ("... .ome text"), besides being sent to social media, the information is displayed in the serial monitor provided by the NodeMcu with the command Serial.print ().

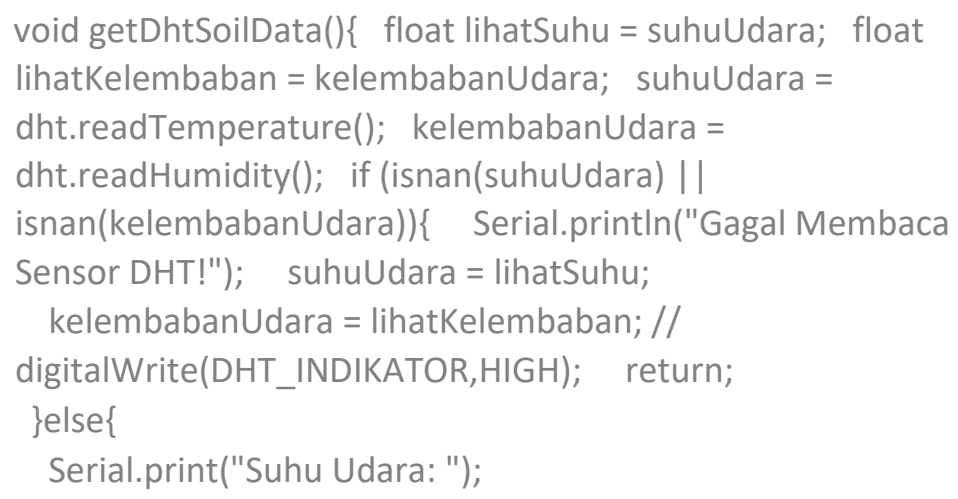


Serial.printIn(suhuUdara);

Serial.print("Kelembaban Udara: ");

Serial.printIn(kelembabanUdara);

Serial.printIn(" $\mathrm{RH} ") ; \quad$ \}

Blynk.tweet(String("Kondisi Tanaman, Kelembaban Tanah: ") + kelembabanTanah + "

RH\n Suhu Udara: " + suhuUdara + " oc \n Kelembaban Udara: " + kelembabanUdara + " RH");

\}

12. The function of reading the soil moisture sensor

The DHT11 sensor readings with soil moisture are in the same function, namely the getDhtSoilData () function, the purpose is combined into one function to facilitate sending data to social media, the analogRead (soil_pin) function is useful for reading analog signals, because the humidity sensor used by researchers connected to an analog pin from NodeMcu. There is a map function (humidity, 400, 1024, 0, 100) which is also useful for configuring data readings because the sensors used by researchers read data between 100 to 1024. Serial.println function is used if you want to display text or sentences with new lines added or enter.

void getDhtSoilData()\{

\section{//Baca Soil}

Moisture Sensor.

kelembabanTanah = 0;

delay (500);

kelembabanTanah = analogRead(soil_pin);

if(isnan(kelembabanTanah))\{

Serial.printIn("Gagal Membaca Sensor Kelembaban Tanah!"); return; \}

kelembabanTanah = map $($ kelembabanTanah, 400, 1024, 100, 0);

Serial.print("kelembaban Tanah: ");

Serial.printIn(kelembabanTanah);

Serial.println(" RH");

\section{Automatic Control Function}

The function in the code line above is to check soil moisture.

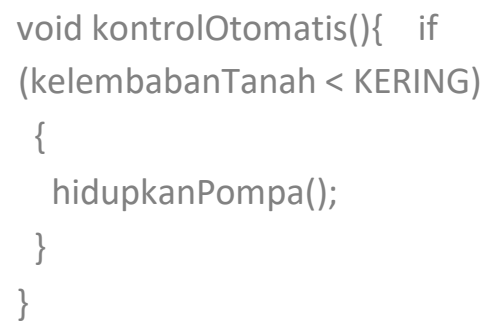

\section{Function Turn on the Pump}

In the above line of code, it is called and gives a value to the Pump variable status $=1$, used as conditioning when pumping water, there is another function, which is Pump control () to turn on the pump which is given delay. 


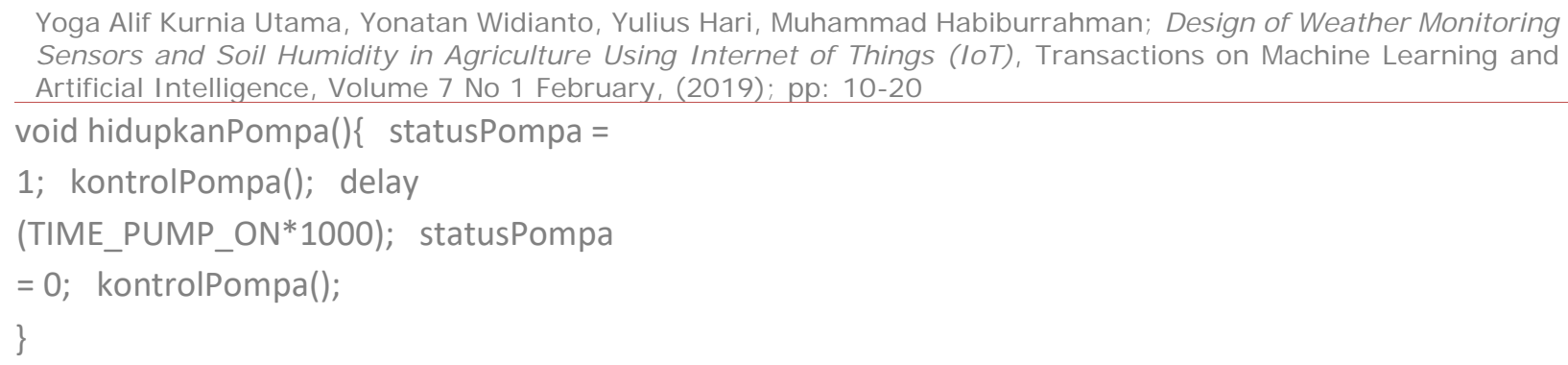

\section{Function Pump}

The code line above is used to turn on the pump by writing digitalWrite (POMPA_PIN, HIGH). The line is checked if the Pump status is equal to 1 , the pump is turned on with a value from digitalWrite $=\mathrm{HIGH}$, then sends a notification to the Blynk application using Blynk.notify (), the notification sent to the blynk application will appear as written on the program. In the line of code, there is also Serial.print () which is useful for sending info to the serial monitor, if the Pump status variable is not equal to 1 then digitalWrite $=$ LOW.

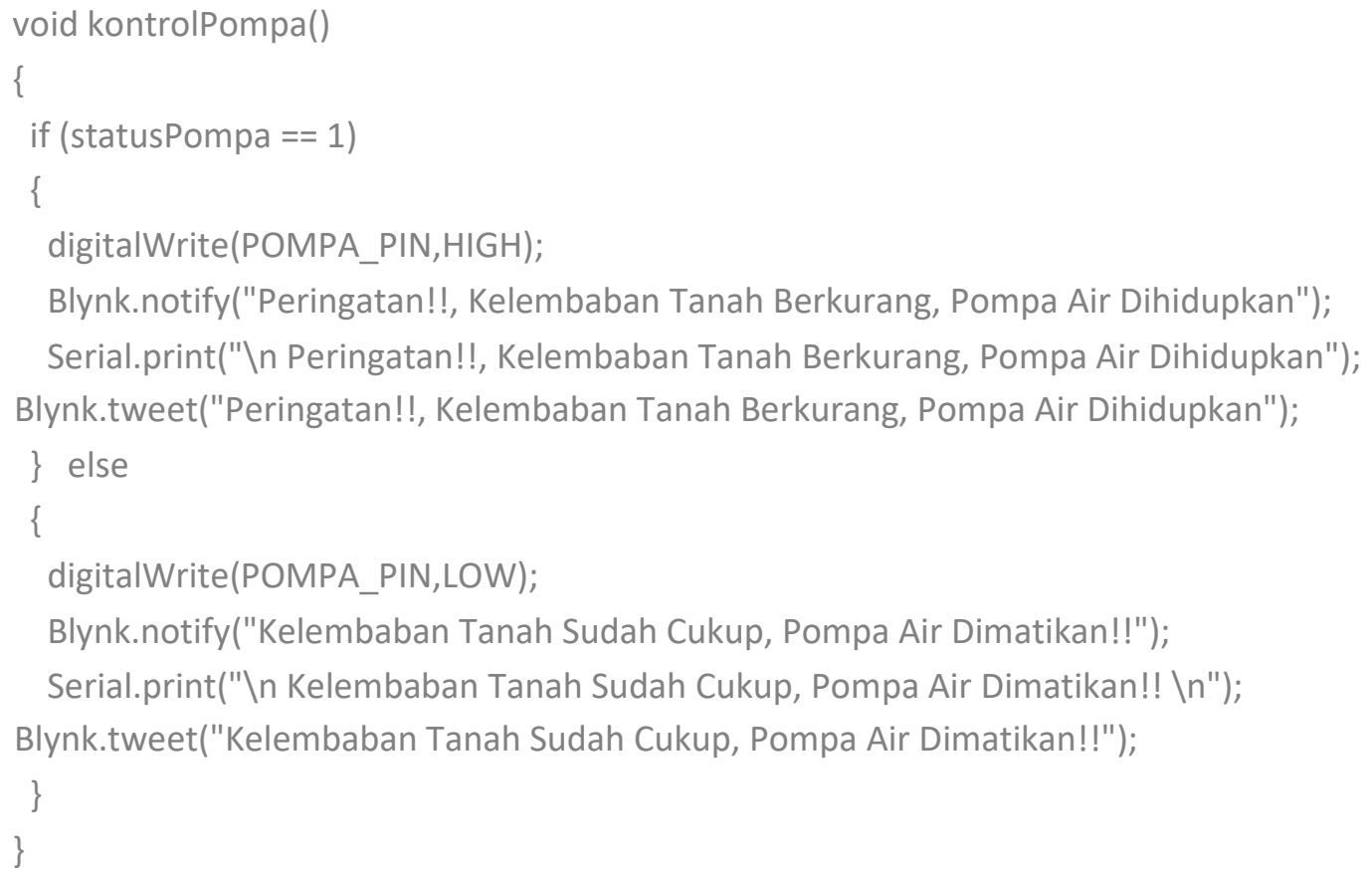

\section{Function Send Sensor Data to Blynk}

The Blynk application has a virtual pin to be able to read the value of the sensors used in this device, therefore to declare which pin to use, write the code as above Blynk.virtuaalWrite (0, temperature Air) means virtual pin 0 (VO) to read the air temperature. Next is a line of code to synchronize the sensor data and virtual pin of the Blynk application.

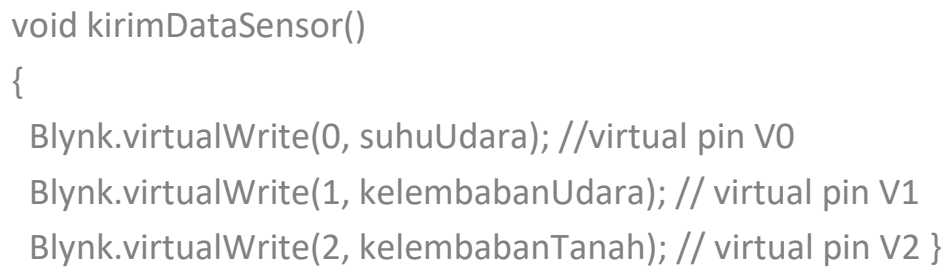




\section{Function Loop}

In writing the program code, there is one function that is useful to run the program repeatedly or continuously, this is the function of the loop, so functions that have been declared with various needs will be running continuously as long as the device is $\mathrm{ON}$. Here is a line of code from the Loop function.

void loop()\{ Blynk.run();

timer.run();

\}

\section{Results and Discussion}

After the tool is finished, the tool is tested. Testing this tool is divided into several dates on the NodeMcu monitor series, Blynk application and social media. Display of data that is raised, among others, air temperature data, air humidity data, soil moisture data, information about the activities of the pump that is active and is dead. The trial display of sensors on Facebook and Twitter can be seen in Figure 5 and Figure 6 below.

\section{Trial Date 23 January 2018 Display of Facebook Website}

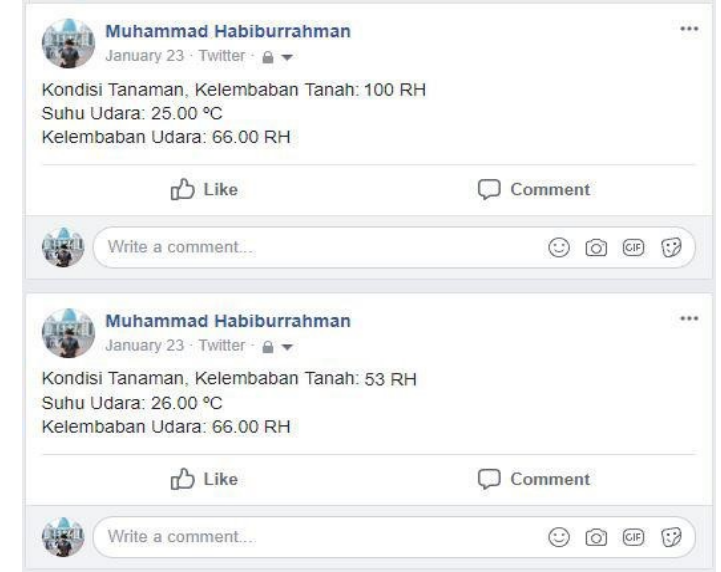

Figure 5. Display of Facebook Website Information January 23.

In the above view, there is info sent from the device, about the current environmental conditions. Data is sent periodically every 2 seconds.

\section{Trial January 23 Display Twitter Website.}

Muh. Habiburrahman @habibsantry.Jan 23

Kondisi Tanaman, Kelembaban Tanah: $100 \mathrm{RH}$

Suhu Udara: $25.00^{\circ} \mathrm{C}$

Kelembaban Udara: $66.00 \mathrm{RH}$

6) Translate from Indonesian

Q $\quad$ ᄂ 0 il

Muh. Habiburrahman @habibsantry·Jan 23

Kondisi Tanaman, Kelembaban Tanah: $53 \mathrm{RH}$

Suhu Udara: $26.00^{\circ} \mathrm{C}$

Kelembaban Udara: $66.00 \mathrm{RH}$

(1) Translate from Indonesian

Q $27 \quad 0$ 川

Figure 6. Display of Twitter Website Information January 23. 
Yoga Alif Kurnia Utama, Yonatan Widianto, Yulius Hari, Muhammad Habiburrahman; Design of Weather Monitoring Sensors and Soil Humidity in Agriculture Using Internet of Things (IOT), Transactions on Machine Learning and

\section{Conclusion}

Based on the implementation of making research ranging from analysis, design to the implementation stage, the author can draw conclusions as follows:

a) This device is very good for use in agriculture because it is very helpful for farmers to monitor and irrigate crops.

b) Farmers can control and monitor remotely because the NodeMcu microcontroller has a wifi device that can connect to the internet, so it can access data freely from anywhere.

c) The Blynk application is very helpful in loT for creating monitoring applications.

d) In addition to opening the Blynk application, there are also notifications received through social media accounts, making it very easy to monitor.

\section{REFERENCES}

[1] Barr, Michael, and Anthony Massa. 2006. Programming Embedded Systems with C and GNU Development Tools. Sebastopol: O'Reilly Media.

[2] Chui, Michael, dkk. 2013. Ten IT-enabled Business Trend for The Decade Ahead. McKinsey Global Institute.

[3] Suresh, P., Daniel, J. V., \& Aswathy, R. H. (2014). A state of the art review on the Internet of Things ( loT ) History, Technology and fields of deployment.

[4] Wang, C., Daneshmand, M., Dohler, M., Mao, X., Hu, R. Q., \& Wang, H. (2013). Guest Editorial- Special issue on the internet of things (IOT): Architecture, protocols, and services. IEEESensors Journal, 13(10), 3505-3508. http://doi.org/10.1109/JSEN.2013.2274906

[5] Utama, Y. A. K., \& Hari, Y. (2017, September). Design of PID disturbance observer for temperature control on room heating system. In Electrical Engineering, Computer Science and Informatics (EECSI), 2017 4th International Conference on (pp. 1-6). IEEE.

[6] Hari, Y., \& Dewi, L. P. (2018). Forecasting System Approach for Stock Trading with Relative Strength Index and Moving Average Indicator. Journal of Telecommunication, Electronic and Computer Engineering (JTEC), 10(2-3), 25-29.

[7] Hari, Y., Dewi, L. P., Santi, C., \& Sembiring, M. J. (2018). Improving Financial Marketing And Accountability With Technology Penetration For The Bag SMEs Community In Gresik, Jawa Timur. Advances in Social Sciences Research Journal, 5(10). 